\title{
Internet Capacity, Network Traffic And Net Neutrality
}

Chris Rose, Walden University, USA

\begin{abstract}
The majority of Internet traffic is exchanged directly on private lines through mutual peering agreements, and although bandwidth usage is growing by about $50 \%$ per year, content publishers have invested in services, such as Akamai to ensure online content is transmitted faster. This means some traffic is already being sent on less crowded connections, and some are cached downstream. So, what about Net Neutrality. Is all Internet traffic really created equal, or is some traffic more equal than others?
\end{abstract}

\section{INTRODUCTION}

emertes Research sounded an ominous warning for the future of the Internet when they first
predicted in 2007 that the Internet cannot sustain itself. Their reasoning was that because there was
an exponential growth in demand for Internet bandwidth, but a linear investment in Internet capacity, there would come a time when demand would outstrip supply.

Capacity in the core and connectivity and fiber layers will outpace all conceivable demand for the near future. However, demand will exceed access line capacity within the next two to four years. Even factoring in the potential impact of a global economic recession on both demand (users purchasing fewer Internet-attached devices and services) and capacity (providers slowing their investment in infrastructure) changes the impact by as little as a year (either delaying or accelerating, depending on which is assumed to have the greater effect.) Nemertes Research, 2009

They claimed that their research was the first time that anyone had ever looked at demand and capacity independently and applied a sort of "Moore's Law of Innovation" to the Internet. They stated as one of their assumptions, that human creativity is unpredictable and boundless and people will always find new and innovative ways to use the Internet as long as it exists. So just as Moore observed that "the density of transistors on a chip will continue to increase exponentially - without knowing or caring about the precise manufacturing techniques that enabled each step of the increase - we noted that people will develop networked applications, without predicting specifically what the next application will be" (Johnson, 2008). Nemertes Research continues to believe that demand will exceed capacity within about four years, "although capacity in the core (including raw fiber capacity and switching/routing capability) continues to outpace demand." This year, in addition to looking at raw bandwidth capacity, they had a look at what they called logical issues, which are "challenges to Internet scalability such as addressing, routing, multihoming and mobility. The news there is even worse: In a nutshell, Internet scalability is rapidly reaching limits due to some architectural issues inherent in the design of the Net." (Johnson, 2008)

Research on Internet bandwidth usage tends to confirm some aspects of the Nemertes Research report since it is estimated that bandwidth usage is growing by an estimated 50\% a year, (Crovitz, 2008). One reason is the growth of virtual workers who work from their homes or virtual offices and another is the growth of high-bandwidth applications gaining in popularity with the home user (Reed, 2008). These applications, such as online gaming and movies also consume enormous amounts of bandwidth. For example, the average DVD movie consumes approximately $2 \mathrm{~GB}$ of bandwidth and newer Blu-ray discs consume many times that amount in fact " 4 million households downloading two high-definition movies per month drives the same Internet demand as 50 million households watching 50 YouTube videos per month. YouTube continues to grow at a fast rate, estimated to be 100 petabytes per month." (Nemertes Research, 2009) 
AT\&T's top lobbyist, James Cicconi, recently warned that we are going to be butting up against the physical capacity of the Internet by 2010 (Wildstrom, 2008) but there are very few other researches who agree with this analysis. "The Internet's core has plenty of bandwidth, so traffic growth really poses the biggest problem for access lines. Fortunately, big gains in capacity in the last mile aren't excruciatingly expensive" (Anderson, 2009b). "Not long ago, the "last mile" to the recipient's premises was a telephone line -a monopoly, of course, thanks to the ancient actions of federal and state governments. Then came competition, links via cable TV, satellite links, the neighbors' Wi-Fi and a half-dozen wireless -telephone options." (Donlan, 2009)

\section{NETWORK TRAFFIC}

An amateur nineteenth century mathematician, William Forster Lloyd, wrote a seminal treatise on the deterioration that would occur in a pasture due to the innate traits of humans. This became known as the "tragedy of the commons" and it was resurrected into mainstream academia by a biologist, Garrett Hardin in 1968. Although Lloyd was examining a shared pasture, his principles can be extended to most shared resources including the Internet (Rose and Gordon, 2003). Basically, if a resource is used at a rate that is near capacity then additional users will only deteriorate the value to all users. This leads to a vicious cycle whereby all users attempt to consume more of the resource so as to be in the same position as they were before the additional user started consuming the resource. Each user is in fact pursuing their own best interest but this ultimately just causes the demise of the resource (Turner, 1993). The Internet is a common, and what any one user does will affect in some way, however small, the other users of the Internet.

It is believed that $20 \%$ of users create $80 \%$ of the traffic (Jenkins, 2009) however, Benoit Felten, a Yankee Group analyst, doesn't believe bandwidth hogs exist and says that ISPs simply look, for example, at the top 5\% of users and claim that they are bandwidth hogs, even though these users might well have configured their computers to download very late at night thereby not causing any bandwidth congestion for other users. He has even issued a challenge to ISPs to let him analyze their actual data and publish the results, whatever the finding. (Anderson, 2009a)

Traffic on the Internet is dependent on cooperation between major users. Currently, there are over 25,000 Autonomous Systems on the Internet. An Autonomous System is independent and can decide who they wish to exchange traffic with on the Internet, so an Autonomous System is not dependent on any third party for access (Berg, 2009). Therefore, to get network traffic from one location to another, the various Autonomous Systems need some sort of interconnection mechanism. They can either do it with a direct arrangement among themselves or indirectly using one or more other networks that will agree to transport the traffic.

According to Berg, 2009, "most network connections are indirect, since it is nearly impossible to interconnect directly with all networks on the globe. (The likes of FLAG and AT\&T might come close, but even they can't claim global network coverage.) In order to make it from one end of the world to another, the traffic will often be transferred through several indirect interconnections to reach the end-user." There are arrangements that networks use for their interconnection arrangements, these are known as peering and transit.

- $\quad$ Peering: this is when two or more Autonomous Systems directly interconnect directly with each other and exchange traffic. Most times this is done without charging a fee since they will both be carrying each other's traffic.

- $\quad$ Transit: this is when one Autonomous System agrees to carry the traffic that is flowing between another Autonomous System and all other networks and since there is no network that connects directly to all other networks, any network that provides transit will of necessity deliver some of the traffic indirectly via one or more other transit networks. (Berg, 2008)

Since everyone depends on everyone else so that they can have complete connectivity, the resulting business environment is characterized by a substantial degree of fluidity, whereby there is no clear demarcation of roles or markets. On fact, because of this, any attempt by one provider to offer a substantially higher guarantee of quality of service is really not possible because of their interdependence since any one attempt at offering better service is dependent on others. (Huston, 2008) 
A provider of transit receives a transit fee for carrying other traffic therefore if traffic stays on their own network it is the cheapest, in fact it is virtually free. In the case of peering, this costs more since a port and line to make the initial connection is needed but if it is an established connection, there is no additional cost. Transit traffic is the most expensive since an estimation has to be made of how much traffic is going to be carried and anything extra costs extra. Therefore, if a provider has, for example, extremely high volumes of Peer-to-Peer use they will at first try to keep that traffic on their own network. If that can't happen, then peering will be the second choice and as a last resort they will pay for transit. Peering usually happens at the place most convenient for the networks and Internet Exchange points are usually established at those locations. (Berg, 2008)

A Tier 1 network does not pay settlements to any other provider, in other words, a Tier 1 network has to peer with every other Tier 1 network. Today, most data is not passing through the big Tier 1 providers. Arbor Networks and the University of Michigan determined that "over the last five years, Internet traffic has migrated away from the traditional Internet core of 10 to 12 Tier-1 international transit providers. Today, the majority of Internet traffic by volume flows directly between large content providers, datacenter/CDNs and consumer networks. Consequently, most Tier-1 networks have evolved their business models away from IP wholesale transit to focus on broader cloud/enterprise services, content hosting and VPNs." (Anderson, 2009b)

\section{NET NEUTRALITY}

In 2007, Comcast tried to control traffic over their network by using some "traffic-shaping" techniques on BitTorrent traffic (BitTorrent being a popular per-to-peer file sharing protocol. It was thought that since many times the heaviest users of BitTorrent are actually digitally trading high quality movies, the move by Comcast was an attempt to protect their cable movie business. Comcast selectively blocked peer-to-peer connections by using deeppacket inspection to monitor their customers' Internet traffic.

The Federal Communications commission (FCC), by a 3-2 vote, determined that the move by Comcast was illegal and the selective blocking of Internet traffic infringed on the users' right to access the Internet and to use whatever application they choose. The Commission said that "Comcast's practices are not minimally intrusive, as the company claims, but rather are invasive and have significant effects...In essence, Comcast opens its customers' mail because it wants to deliver mail not based on the address on the envelope but on the type of letter contained therein." (Kravets, 2008). However, networks are not allowed to offer different levels of service so as to allocate their scarce bandwidth since they might discriminate if they have their own online offerings (such as Comcast) but they should be allowed to charge different rates for different types of services as long as there is no discrimination. There must be transparency, but networks have to be efficiently managed. (Crovitz, 2008)

Those who complain that the Internet needs to be regulated point to the business model that was used years ago by AOL when they first started demanding open access when broadband threatened their dial-up business. They claim that AOL's business model depended on their users getting free access to resources that were being paid for by telephone customers. "AOL users were dialing up and keeping a line open for days or even weeks at a time -- yet faced no cost for the disproportionate capacity they used up. This is the basic pricing model the biggest Web companies (especially Google) seek to preserve on the Internet. Their business models are built on a Web that makes their services appear "free" to users."(Jenkins, 2009)

Ironically, Google, one of the major supporters of a free and open Internet, found themselves in the very same predicament. AT\&T, who are on the other side of the Net Neutrality debate to Google, recently complained to the FCC that Google, in their Google Voice service, violates the FCC's Net Neutrality guidelines. It is thought that AT\&T was just trying to score some debating points in this debate and point out to the FCC and Google that sometimes a provider has to treat some networks differently. The issue under contention was a decision by Google not to connect Google Voice customers to some conference calling and some other remotely located telephone lines because of excessive access charges by the providers of those lines. AT\&T claimed Google was discriminating since AT\&T is required to connect its telephones to all lines. Google claimed its Google Voice service is not a telephone service and is not covered by the same rules. (Hansell, 2009) 
The US Congress is currently considering HR3458-the Internet Freedom Preservation Act of 2009 which many believe is necessary to ensure that all consumers and providers, no matter how big or small have equal access and to make sure that consumers and not large content providers in secret deals with service providers determine what and how content is accessed over the Internet.

\section{IS THE NET NEUTRAL?}

Google, in 2008, negotiated with ISPs to deliver content which demanded more bandwidth, such as YouTube videos, more quickly. The idea was that Google would co-locate its servers in the physical facilities of the broadband providers so that they could accelerate access to its own content. On the surface, this seems to violate the Network Neutrality principle since some traffic would now be getting preferential treatment. Google claimed that this was only caching of content and this would benefit consumers. Even Net Neutrality backers stated that this would mean better management and less congestion of networks. In this case, both sides agreed that efficient management of networks on the Web is beneficial.

"At one level, the debate about network neutrality reflects the long-running competition in media between those who create content and those who distribute it. This historically pitted movie producers against movie theaters and television studios against cable companies. Internet companies such as Google, Yahoo and Microsoft don't want to have to pay tolls to the companies that provide the Web infrastructure. But someone has to pay to keep the network up to speed" (Crovitz, 2008). Microsoft, Google and entertainment distributers all believe that only content owners should charge for content and that transmission should be a flat fee. (Donlan, 2009)

Nobody could argue that Google does not have a right to make arrangements with services such as Akamai, to provide so called 'edge caching' of content so that large files, such as online video, it can be delivered to users more quickly and efficiently. Even Amazon made special arrangements with Sprint so that digital books for the Kindle electronic reader can be downloaded in a quickly. In fact, some companies would even like to get unto to Internet2, just to be able to offer better service. This is nothing new, because in every other sphere of business large well-funded companies compete by providing better and more reliable service than their rivals. (Crovitz, 2008)

AT\&T and other wireless firms, have never been subjected to the same kind of Internet scrutiny as other companies that provide wired cable or DSL Internet connections. AT\&T said it supports the principle of Net Neutrality and the FCC effort to strengthen its legal authority to regulate the Internet. However AT\&T "had concerns about expanding the rules to cover wireless networks. The company would be "very disappointed if [the FCC] has already drawn a conclusion to regulate wireless services despite the absence of any compelling evidence of problems or abuse that would warrant government intervention."(Schatz \& Johnson, 2009)

\section{CONCLUSION}

The Internet, if viewed as a sector of our economy, provides three million jobs, supports 20,000 Internetrelated small businesses, and accounts for about $2 \%$ of our gross domestic product. "Companies like Yahoo!, Google, Amazon, eBay, Facebook, Salesforce.com, Expedia, Monster, and NetFlix, alone represent nearly $\$ 300$ billion of market capitalization. Similarly, thousands of other firms, including Apple, Disney and Wal-Mart to name only a few, complement their businesses through the distribution and audience aggregation power of the Internet."(Baker\& Lily 2009)

Any changes or added regulations to such an important sector of our economy should be carefully considered since it would be extremely difficult to guarantee or even define Net Neutrality in legislation that can be enforced. If providers discriminate to favor their own content or applications, the end user really has no technical solution to maintain their network performance. On the other hand, if there is sufficient bandwidth even during peak hours, then it doesn't matter if providers give their content or applications priority, but giving all content equal bandwidth availability is actually the fairest method of all. Occasionally there are times when bandwidth allocation schemes are required, since during disasters phone networks have already done this. For the wired Internet, they might have to implement this capability for first responders, relief organizations or the military. (Passmore, 2006) 
Currently, regulators treat the Net as if it were some sort of common carrier such as a railroad or bus system, not thinking about efficient network management, speed, availability and pricing. "Network neutrality is a social issue, not a business issue. The Internet has changed just about everything and that puts it on a par with the telephone service, the highway system and the power grid" (Gibbs, 2009) and "commercial motives could stifle entertainment, culture, and political diversity" (Joch, 2009). There is no longer a monopoly on methods to connect to the Internet, and in fact, adding more wires or more radio links is now easier than ever. "As long as local, state and federal regulators stay out of the way, consumers will have as many choices as they need and want." (Donlan, 2009)

\section{REFERENCES}

1. Anderson, N. "Bandwidth hogs" join unicorns in realm of mythical creatures. Ars Technica. 2009, September.3, Retrieved on 12/3/2009 from http://arstechnica.com/tech-policy/news/2009/12/bandwidthhogs-dont-even-exist-says-analyst.ars

2. Anderson, N. The Internet is about to die. Literally die! Ars Technica. October 14, 2009. Retrieved 11/26/09 from http://arstechnica.com/tech-policy/news/2009/10/the-internet-is-about-to-die-literally-die.ars

3. Baker, M., Lilly, J. Net Neutrality: Spur to Entrepreneurship. Wall Street Journal. (Eastern edition). New York, N.Y.: Oct 30, 2009.

4. Berg, R. How the 'Net works: an introduction to peering and transit September 2, 2008, Ars Technica . Retrieved 12/1/2009 from http://arstechnica.com/old/content/2008/09/peering-and-transit.ars

5. Crovitz, L. Information Age: 'Network Neutrality'? Never Mind . Wall Street Journal. (Eastern edition). New York, N.Y.: Dec 22, 2008

6. Donlan, T. A Rule Too Far. Barron's. New York, N.Y.: Oct 12, 2009. Vol. 89, Iss. 41

7. Gibbs, M. Network neutrality: Doing the right things. Network World. Southborough: Oct 5, 2009. Vol. 26, Iss. 30;

8. Hansell, S. AT\&T Says Google Voice Violates Net Neutrality Principles. September 25, 2009, The New York Times. Retrieved 12/1/09 from http://bits.blogs.nytimes.com/2009/09/25/att-says-google-voiceviolates-net-neutrality-principles/

9. Huston, G. Interconnection, Peering, and Settlements, 2008. Retrieved 12/1/09 from http://www.isoc.org/inet99/proceedings/1e/1e 1. htm

10. Jenkins, H. Neutering the 'Net. Wall Street Journal. (Eastern edition). New York, N.Y.: Sep 23, 2009

11. Joch, A. Debating Net Neutrality. Association for Computing Machinery. Communications of the ACM. New York: Oct 2009. Vol. 52, Iss. 10

12. Johnson, J. About those 'Net capacity issues: There's more. Network World. Southborough: Dec 8, 2008. Vol. 25, Iss. 47

13. Johnson, J. The Internet sky really is falling. Computerworld. May 6, 2009

14. Kravets, D. Comcast Ordered to Allow Free Flow of File Sharing Traffic. August 1, 2008. Retrieved 11/30/09 from http://www.wired.com/threatlevel/2008/08/fcc-declares-co/

15. Nemertes Research (2009). Internet Interrupted: Why Architectural Limitations Will Fracture the 'Net. Retrieved on May 1, 2009 from http://www.nemertes.com/studies/internet_interrupted_why_architectural_limitations_will_fracture_net

16. Nelson, R. Keep your hands off my Internet content. EDN. Boston: Oct 8, 2009. Vol. 54, Iss. 19

17. Passmore, D. Bringing Fairness To The Net Neutrality Debate. Business Communications Review. Hinsdale: Jun 2006. Vol. 36, Iss. 6

18. Rose C. and Gordon J. (2003) Internet Security and the Tragedy of the Commons, International Business \& Economics Research Journal, Vol. 1, No. 2, pages $67-71$.

19. Turner R. (1993, January 21). The tragedy of the commons and distributed AI systems. Proceedings of the $12^{\text {th }}$ International Workshop on Distributed Artificial Intelligence, Hidden Valley, PA.

20. Schatz, A. \& Johnson, F. Internet Providers Push Back Against 'Net Neutrality' Proposal. Wall Street Journal. (Eastern edition). New York, N.Y.: Sep 22, 2009

21. Wildstrom, S. The Internet has lots of Running Room. Business Week. New York: Sep 15, 2008. , Iss. 4099 
NOTES 